\title{
Pt Nano-Layer Formation by Redox Replacement of Cu Adlayer on Au(111) Surface
}

\author{
Deyu Qu, Chi-Woo J. Lee, ${ }^{*}$ and Kohei Uosaki*
}

\author{
Department of thanced Materials Chemistry, College of Science and Technologv, Korea Lniversity, Jochiwon, \\ Chungnam 339-700. Korea. ${ }^{*}$ E-mail: cwleeiákorea ack \\ 'Physical Chemistry Laboratory, Division of Chemistry, Graduate School of Science, Hokkaido Iniversitv: \\ Sapporo 060-0810, Japan \\ Received September 11, 2009. Accepted October 16, 2009
}

Key Words: Pt. Cu. Au( 111$)$. Redox replacement

Platimum is one of the most important catalysts for many chemical and electrochemical reactions. 'Deposition of small amount of platimum on metal surfaces has been shown to improve the electrocataly tic properties of the metal electrodes. " Platinum does not exhibit underpotential deposition (UPD) behavior and studies showed that electrochemical deposition of platinum on Au(111) surface from platinum complex solutions proceeded with a layer by layer grow th mode to form a multilayer of $\mathrm{Pt}^{3}$ or produced 3D clusters and a cauliflower-like Pt appearance ${ }^{4}$ or Pt nanoparticles. ${ }^{5,6}$ Recently a new method which is now recognized as surface limited redox replacement reaction $\left(\mathrm{SLR}^{3}\right)$. was presented to prepare a Pt submonolayer/monolayer on gold surface. ${ }^{7}$ This method has been widely used to fonma Pt adlay'er on golds for different purposes. 8,9

Since controversy exists on the platinum film electrochemically deposited by using $\mathrm{PtCl}_{6}^{3-}$ versus $\mathrm{PtCl}_{4}{ }^{3-}$, 3.4 and a single UPD Cu replacement with $\mathrm{Pt}(\mathrm{II})$ ions can yield a full monolayer but the previous elaboration was limited to $\mathrm{PtCl}_{6}{ }^{2-}$ case only, we investigated the redox replacement of UPD $\mathrm{Cu}$ adlayer on $\mathrm{All}(\mathrm{III})$ in $\mathrm{PtCl}_{+}{ }^{--}$solutions as a function of time by using X-ray photoelectron spectroscopy (XPS). cyclic voltammetry (CV), and scanning tunneling microscopy (STM)

All chemicals were of the best quality available commercially and used as received. $\mathrm{A} \mathrm{Au}$ ( 111 ) single crystal was prepared as before. ${ }^{16}$ XP spectra were obtained using a Rigakudenki model

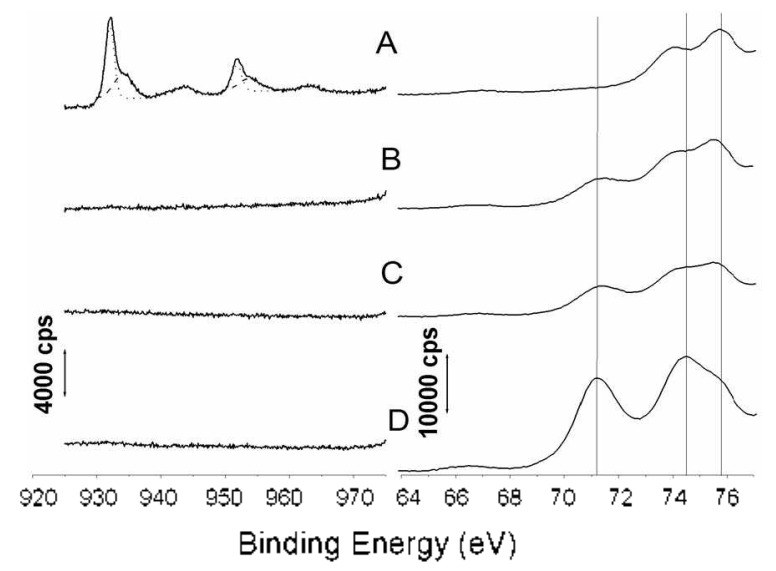

Figure 1. XP Cu $2 p$ and Pt 4 t spectra of the UPD Cu/Au( I11) electrodes immersed in $\mathrm{PtCl}_{4}{ }^{2 \cdot}$ solution at different replacing time; $(\mathrm{A}) 0$ minute (before the replacement), (B) 10 minutes, (C) 20 minutes, and (D) 240 minutes.
XPS-7000 X-ray photoelectron spectrometer with an Mg Ka radiation. STM measurements were carried out as before. ${ }^{[1}$

Fig. 1 shows the XP spectra of $\mathrm{Cu}$ and $\mathrm{Pt}$ regions as a function of time. The $\mathrm{Cu} 2 \mathrm{p}_{\mathrm{s}: \mathrm{P}}$ and $\mathrm{Cu} 2 \mathrm{p}_{1: 2}$ peaks range 932 to $934 \mathrm{eV}$ and 951 to $954 \mathrm{eV}$. respectively, and each of them can be best fitted with two peaks. Each of these two peaks corresponds to metallic $\mathrm{Cu}$ (dotted line) and copper oxide (dashed line). The $\mathrm{Cu}$ $2 \mathrm{p}_{3: 2}(932.2 \mathrm{eV})$ and $\mathrm{Cu} 2 \mathrm{p}_{1: 2}(952.0 \mathrm{eV})$ peaks in Fig l A totally disappeared after 10 minutes incubation (Fig. 1B). Sinultaneously $\mathrm{Pt}+\mathrm{f}_{7: 2}(71.2 \mathrm{eV})$ and $\mathrm{Pt}+\mathrm{f}_{5: 2}(74.5 \mathrm{eV})$ peaks ${ }^{12}$ appeared. reflecting that the $\mathrm{Pt} / \mathrm{Cu} \mathrm{SLR}{ }^{3}$ rapidly occurred. The four other peaks in XP spectra of Cu $2 \mathrm{p}$ (Fig. IA) with the binding energies of $933.4,941,953.2$ and $962 \mathrm{eV}$ are identical to those in the XP spectra region of Cu oxides and sinular to the XP spectra of UPD Cu on Au reported previously. ${ }^{13.14}$ The appearance of $\mathrm{CuO}$ is due to exposure of the sample electrode to the ambient enviromment before the XPS measurements. It was reported that only a moderate amount of copper oxide was formed on UPD Cu/Au surface even when the UPD Cu surface was deliberately oxidized by oxỵgen plasma. ${ }^{13.14}$ A Au $5 p_{1: 2}$ peak $(75.8 \mathrm{eV})$ was found in the sinular intensities through Fig. IA to ID. Another peak $(66.5 \mathrm{eV}$ ) was also found with the same behavior as Au $5 \mathrm{p}_{1: \text { p }}$ peak in Fig 1 . This peak tenporarily assigned to the unidentified species existed in the chamber of XPS. One should note that the $\mathrm{Pt}+\mathrm{f}$ signal does not remain the same after replacement. $\mathrm{Pt}+\mathrm{f}_{-2}$ peak intensity was found to be 5011.5000 and $15660 \mathrm{cps}$ for the replacement time of 10.20 and $240 \mathrm{~min}$. respectively. The relative amount of UPD Cu and formed Pt at different replacement time on the Au surface was determined by $\mathrm{Cu}_{\mathrm{LP} \text { : }}$ :

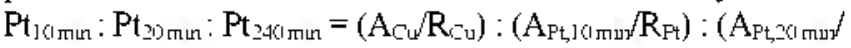
$\left.\mathrm{R}_{\mathrm{Ft}}\right)$ : $\left(\mathrm{A}_{\mathrm{Pr} . \mathrm{At}}, \mathrm{min} / \mathrm{R}_{\mathrm{F}}\right)$. where $\mathrm{A}$ is the peak area and $\mathrm{R}$ is the atomic sensitivity factor. ${ }^{12.15 .16}$ Using $R_{C u}$ and $R_{\mathrm{Ft}}$ of 4.4 and 6.3 , respectively. ${ }^{16}$ the ratio was found to be $1: 0.17: 0.23: 0.93$

The $\mathrm{Pt} / \mathrm{Au}$ electrodes with different incubation time were also tested by $\mathrm{CV}$ measurements in $0.05 \mathrm{M} \mathrm{H}_{2} \mathrm{SO}_{4}$ solution (Figure 2a). The potential was initially scanned from $0.1 \mathrm{~V}$ to negative direction. The platinum oxide reduction peak around $0.4 \mathrm{~V}$ as well as a well-shaped hydrogen adsorption/desorption feature in the potential region of $+0.1 \mathrm{~V}$ to $-0.20 \mathrm{~V}$ were observed. similar to that of a polycrystalline Pt reported previously. ${ }^{1 \text { ? }}$ The voltammogram is different from that of Pt film fonmed via replacement of UPD $\mathrm{Cu}$ from $\mathrm{PtCl}_{6}{ }^{3-}$ solution but similar to the one through $\mathrm{PtCl}_{4}{ }^{2-8}$. The charges associated with the desorption of hydrogen on the platinum were found to be 62. 107. 103 
(A)



(B)



(C)

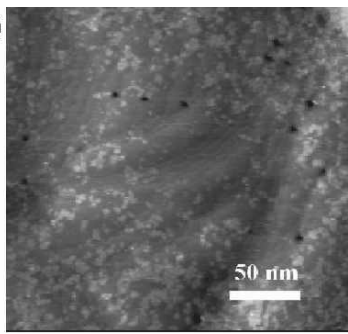

Figure 2. (A) Cyclic vollammogram of PtiAu electrode in $0.05 \mathrm{M}$ $\mathrm{I}_{2} \mathrm{SO}_{4}$ solution with potential scan rate of $20 \mathrm{mV} \mathrm{s}^{-1}$. Incubation time in $0.5 \mathrm{mM} \mathrm{PtCl}^{2-}$ solution: (solide) 5 minules. (dash) 10 minutes. (dot) 20 minutes and (dash dot) 4 hours. (B) \& (C) SIM images $\left(\mathrm{U}_{\mathrm{t}}-\mathrm{l}(00\right.$ $\mathrm{mV}, \mathrm{I}_{\mathrm{L}}-100 \mathrm{pA}$ ) of $\mathrm{P} \mathrm{t}$ li]m on Au( 111 ) electrode obtained al ter $240(\mathrm{~B})$ and $10(\mathrm{C})$ minutes replacement of Cu adlayer in $0.5 \mathrm{mM} \mathrm{K}_{2} \mathrm{PtCl}_{4}$ solution. The electrodes were rinsed by $\mathrm{Pl}$ ions liee sulluric acid solution before $\mathrm{CV}$ and SIM measurements.

and $155 \mu \mathrm{C} \mathrm{cm}^{2}$ at the incubation time of $5,10,20$ and $240 \mathrm{~min}$, respectively. These values are equal to about $30 \%, 51 \%, 49 \%$ and $74 \%$ ol the charge associated with the adsorption/desorption of one hydrogen tull monolayer on a Pt 111 ) surtace $(210$ $\left.\mu \mathrm{C} \mathrm{cm}^{-2}\right)$, ${ }^{18}$ sugesesting that even afier 4 hours immersion, a lull monolayer of Pt was 110 formed and bare Au surface still existed as was found in XPS experiments. The voltammogram litle changed with lirther incubation time.

The STM images of the electrodes taken alter 240 and 10 minules incubation are shown in Figure $2 \mathrm{~B}$ and $\mathrm{C}$, respectively. Pt nano-clusters and bare Au(1II) surface are scen in both cases. The data show that larger and more uncovered $\wedge$ u( 111$)$ surlace was found with the smaller incubation time. The STM images are ditiorent from the one in the previous neport, where apparently the entire $\Lambda u(111)$ surlace was covered by a unitorm Pt fĭlm and no large gold surface was observed. I Iowever, Pt clusters with 0.3 to $0.5 \mathrm{~mm}$ high were lound in the close up STM image. In addition, ultrafine and narrow regions of bare gold surface were seen between the l't nano-clusters in the SIM image of the original work. The dillerence between this study and the previous work may come from the use of ditferent platinum ions. In the present calse $\mathrm{PtCl}_{4}{ }^{2}$ ions were hired, one $\mathrm{Pt}$ atom replaced one Cu atom on the Au surface and the significant congregation of deposited Pt atoms could oceur at lirst and then the atomic rearrangements proceed as lime passed out.
When the sires of the atomic nuclei (Cu: $0.256 \mathrm{~nm}$, P1: 0.278 nm, Aul: 0.288 num) are considered, the commensurate l't (111) surface may be expected if all the C $u$ atoms were replaced by Pt atoms at the same location. The above results of XPS, CV, and STM demonstrale that the UPD copper was completely removed upon electron transier, that the adsoption of Platoms was less than $100 \%$ with aggregation in some prelerred locations so that signiticant portion of Au substrate was unoccupied, and that the deposited platinum atoms were mobile for hours after replacing copper atoms. SL.R ${ }^{3}$ is composed of charge transler, adsoption of the reduced particles, and the rearmangement of the adsorbed atoms. Except the electron transler, the other processes are slow and the details of $S T, \mathrm{R}^{2}$ remain to be exploned. This is the first example to show the long-term atomic rearrangement or relasation in $\mathrm{SLR}^{3}$.

In summary, kinetic aspects of Pt monolay er lomation by a sponlaneous redox replacement ol UPD Cu adlayer on $\Lambda$ ( 111 ) surlace were studied. ITPD Cu adlayer was totally removed inmediately alter it was exposed to the solution containing $\mathrm{PtCl}_{4}{ }^{2-}$ ions. The deposited platinum atoms were mobile for hours that atomic rearrangements took place. l’t clusters and uncovered $\Lambda$ surface were detected.

Acknowledgments. This work was financially supported by Korca University. We are grateful to Protessor K. Shimazu and Dr. T. Matsuda, Holkaido University for use of the Xl'S instrument.

\section{References}

1. Peng, L.: Yane, Il Fano Todw 2009. 4. 143.

2. Rand. D. A. J.: Woods. R. J. Llectrownal. Chem 1973. 44. 83.

3. Uosali, K.: Ye. S.: Naohara H.: Oda. Y: Haba T.; Kondo. T.J. Phos. Chem. B 1997. 101, 7566 .

4. Waibel. H.-F.: Kleinert. M.; Kibler. L. A.: Kolb. D. M. Electrochimict ictu 2002. $\$ 7.1461$

5. Nagahara. Y.: I Iara, M.; Yoshimoto, S.; Inukai, J.: Yau, S.-L.: Itaya K. J. Pln! (hem. B 2004, 108, 3224

6. Kim, J.: Jung, C.; Rhee, C. K.: I.m, T.-H. Iangmuir 2007, 23. 10831 .

7. Brankonic, S. R.: Wang. I. X.: Adzic. R. R. Surf. Sci. 2001. 77. $\mathrm{L} 173$.

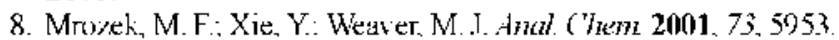

9. Kim. Y.G.: Kim, J. Y: Vairavapandian, D.: Stickney, J. I. J. Ploss. Chem $B$ 2006, 110, 17908 and references therein.

10. Qu. D.: Morin. M. J. Electromal Chem. 2004. 565.235.

11. Song. M.-B.; Jang. J.-M.; Bac, S.-L.; Lce, C.-W. Langmuir 2002. 18,2780

12. Wagner. C. D.: Riggs. W. D.: Davis. I .. F.: Moulder T. F.: Muileuberg. G. F. Hoidhook of I-ron Photolectmon Spectroscom, Perkin Elmer Corp.: Eden Praine. 1979.

13. Tamborini, F. P.. Campbell. J. K.: Crooks, R. M. Itmgmir 1998. 14, 640 .

14. I,in, S.-Y.; Twii, T.-K.; Iin, C.-M.; Chen, C.-H.: Chan, Y.C.; Chen, H.-W. I.angnnir $2002,18,5473$

15. Qu, D.: Uosaki. K. J. Plns. C/hem. B 2006. Ho, 17570.

16. Pracical Surface Analysis Vohme 1. Anger and Y-ray Phowelectron Spectroscopy Briges. D.: Scah. M. P.. Lds.: John Wilcy and Sons: Chichester. IJ 1900: Appendix 6.

17. Conway B. F. Prog Suf. Sici 1995 49, 331.

18. Trassati, S.; Petrii, O. A. Pure Appl Chem 1991, 63, 712. 